Original Article

Artigo Original

Vanessa Clarizia Marchesin ${ }^{1}$ Maria Cecília Martinelli lório ${ }^{1}$

Keywords

Adult

Hearing Aids

Hearing Loss

Speech Perception

Rehabilitation

Descritores

Adulto

Auxiliares de Audição

Perda Auditiva

Percepção da Fala

Reabilitação

Correspondence address:

Vanessa Clarizia Marchesin

Rua Botucatu, 802, Vila Clementino,

São Paulo (SP), Brazil, CEP: 04023-900.

E-mail:vclarizia@hotmail.com

Received: 09/02/2014

\section{Study of the long-term effects of frequency compression by behavioral verbal tests in adults}

\author{
Estudo dos efeitos de longo prazo da \\ compressão de frequências por meio de testes \\ comportamentais verbais em adultos
}

\begin{abstract}
Purpose: To verify the effect of long-term use of hearing aids with frequency compression for verbal behavior tests and daily activities. Methods: Thirty-two adults, aged between 30 and 60 years old, with moderate to severe sensorineural hearing loss at high frequencies with steeply sloping configuration were divided into two groups: 16 with hearing aids with frequency compression algorithm enabled and 16 not enabled. All participants underwent the detection tests of consonant sounds, monosyllable recognition in quiet environments, identification of fricative monosyllables, and Abbreviated Profile of Hearing Aid Benefit (APHAB) questionnaire in five times throughout a 12-month trial. Results: Detection of consonant sounds, recognition of monosyllables in quiet environments and identification of fricative monosyllables improved significantly with frequency compression enabled. Participants had their APHAB scores improved whether they were adapted to the frequency compression or not. Conclusion: Frequency compression provides the anticipated improvement in audibility, detection of high-frequency consonant sounds, and recognition of monosyllables.
\end{abstract}

\section{RESUMO}

Objetivo: Verificar o efeito do uso de longo prazo de próteses auditivas com compressão de frequências em testes comportamentais verbais e atividades diárias. Métodos: Trinta e dois adultos, com idade entre 30 e 60 anos, com perda auditiva neurossensorial de grau moderado a severo em altas frequências com configuração descendente foram distribuídos em dois grupos: 16 com próteses auditivas com o algoritmo de compressão de frequências ativado e 16 não ativado. Foram submetidos a testes de detecção de sons consonantais, reconhecimento de monossílabos no silêncio, identificação de monossílabos com fricativos e questionário Abbreviated Profile of Hearing Aid Benefit (APHAB) em cinco momentos ao longo de 12 meses. Resultados: A detecção de sons consonantais, o reconhecimento de monossílabos no silêncio e a identificação de monossílabos com fricativos melhoraram significantemente com a compressão de frequências ativada. Os participantes apresentaram melhora das pontuações do APHAB independentemente de estarem adaptados ou não à compressão de frequências. Conclusão: A compressão de frequências propicia a melhora antecipada da audibilidade, detecção de sons consonantais de altas frequências e o reconhecimento de monossílabos.

Study carried out at the Speech-Language Pathology and Audiology Department, Universidade Federal de São Paulo - UNIFESP - São Paulo (SP), Brazil.

(1) Speech-Language Pathology and Audiology Department, Universidade Federal de São Paulo - UNIFESP São Paulo (SP), Brazil.

Financial support: Coordenação de Aperfeicoamento de Pessoal de Nivel Superior - CAPES.

Conflict of interests: nothing to declare. 


\section{INTRODUCTION}

In the last decades, audiology professionals have faced the challenge of achieving a satisfactory adaptation and selection of hearing aids in patients with sensorineural hearing loss, especially those with steeply sloping configuration. These patients usually have normal or almost normal hearing sensitivity in low and medium frequencies and were elected as candidates with restrictions for the use of amplification due to technological limitations ${ }^{(1)}$ and to poor speech perception in noisy environments, once high-frequency amplification is not enough to provide good audibility of speech sounds and cannot be reused because of organic limitations ${ }^{(2)}$.

In view of this, some researchers recommend the prescription of little or none amplification in high frequencies during adaptation of hearing aids for patients with steeply sloping hearing $\operatorname{loss}^{(3,4)}$.

Conversely, it is known that information input at high frequencies can significantly improve speech perception, especially in noisy environments ${ }^{(5-7)}$. Other studies suggest that extending the frequency band can improve speech sounds detection ${ }^{(8-10)}$ and fricative sounds perception ${ }^{(11)}$.

Aiming to resolve difficulties in adaptation of hearing aids in patients with steeply sloping hearing loss, algorithms capable of lowering frequency have been created, where speech sounds information is moved to a lower frequency band that is audible for the patient. Currently, many digital hearing aids are able to lower frequencies in real time. These techniques can help patients detect and distinguish high-frequency phonemes, thus enhancing communication ${ }^{(12,13)}$.

These techniques include frequency compression (FC), where the input is processed with frequency lowering by means of compression of the sound frequency band starting from a frequency cutoff and with specific compression ratio ${ }^{(14)}$. Recent studies suggest that FC may bring greater benefits to adults and children ${ }^{(15-17)}$, and the most common clinical results are spontaneous acceptance by the user, fast acclimatization during adaptation of hearing aid, significant improvement in quality of voice ${ }^{(14,16,18)}$, acoustic feedback problems, and issues related to the excessive volume resulting from amplification of high frequencies ${ }^{(14)}$.

Some researchers have investigated the effects of FC in adults with hearing loss at high frequencies ${ }^{(19)}$. No significant enhancement in performance was seen in comparison to FC in conventional technology. In contrast, studies conducted with children to assess the effect of FC in sound detection showed that FC improved it. Some authors have stated that the detection of $/ \mathrm{s} /$ and $/ / /$ was more successful when $\mathrm{FC}$ was activated ${ }^{(16)}$. Likewise, other authors have shown that the detection of /s/ was more successful with FC after six months of experience ${ }^{(20)}$.

A period of acclimatization may be needed so one can acknowledge the benefits of $\mathrm{FC}^{(16)}$. However, the long-term performance with $\mathrm{FC}$ for compressed frequency signal has been given little attention to date. A study that assessed 15 children adapted to hearing aids with FC showed benefits after six weeks of adaptation ${ }^{(20)}$. Additional benefits of FC after a six-month period were seen, compared to initial measures without FC as to consonant sound detection and speech recognition in noisy conditions. The authors considered the need of longer adaptation periods aiming at fullest advantage as evidence. Recently, some authors investigated possible effects of acclimatization of FC in children. They presented a series of cases of children adapted with FC followed up at regular intervals for about 30 weeks after the adaptation of hearing aids. Long-term additional benefits of FC were proven ${ }^{(21)}$. A study conducted with adults showed speech recognition in noisy conditions and detection of consonant sounds in quiet environments after prolonged periods of use (1-121 weeks) of amplification with FC. Consonant sound detection in speech recognition in quiet environments, but not in noisy conditions, was significantly better when FC was activated. No significant correlation between time of FC experience and its benefits was found ${ }^{(22)}$.

No study has investigated the period of acclimatization required to achieve fullest advantage of FC. Therefore, important issues related to FC technology and to the use of this algorithm in adults adapted to hearing aids remain unsolved. The purpose of this longitudinal study was, therefore, to verify the long-term use of hearing aids with FC in adults with verbal behavior tests and daily activities.

\section{METHODS}

This is an experimental research with a convenience nonprobabilistic sample. The project was approved by the Ethics Committee of Universidade Federal de São Paulo, protocol CEP 0855/10. All participants were informed about the objectives and methodology of the study and agreed to participate voluntarily after signing the informed consent form.

Exclusion criteria were the following:

1. hearing level fluctuations or changes;

2. asymmetry in air threshold greater than $15 \mathrm{~dB}$ in two or more frequencies;

3. air-bone gap greater than $15 \mathrm{~dB}$ at any test frequency;

4. abnormal middle ear function; and

5. experience with hearing aids.

Adults comprising the sample were randomly selected in an assistance center for the hearing impaired at Núcleo Integrado de Assistência, Pesquisa e Ensino em Audição (NIAPEA), in a Public Hospital, after initial assessment of medical records.

The sample comprised 32 adults with moderate to severe bilateral sensorineural hearing loss at high frequencies, being 16 women and 16 men aging 30-60 years old (mean $=46$ years; standard deviation $(\mathrm{SD})=11$ ) and with mean 9.2 schooling years $(\mathrm{SD}=3)$. They were divided into two groups with 16 adults each, paired by age, hearing loss level, and years of study. The experimental group had FC activated and control group had FC deactivated.

Participants that were new users of hearing aids were adapted with hearing aids Phonak Naída III SP BTE and acrylic invisible ear molds with $2.5-\mathrm{mm}$ bilateral ventilation, according to NAL/NLI prescriptions. FC patterns were prescribed by the 
software Phonak. After assuring audibility of sounds in high frequencies, all participants were oriented as to effective use of at least six daily hours of hearing aids.

Individuals were submitted to the following verbal behavior tests: detection of consonant sounds /s/ and / $/$ /, rates of speech perception and spoken word recognition (SPWR) with recorded monosyllables, rates of fricative phoneme perception (FPP), and Abbreviated Profile of Hearing Aid Benefit (APHAB) questionnaire. The study was divided into five moments of evaluation: preadaptation of hearing aids (T0), one month (T1), three months (T2), six months (T3), and 12 months (T4) after adaptation period.

\section{Detection of consonant sounds}

The Ling test is traditionally composed of six sounds: $/ \mathrm{m} /$, $/ \mathrm{a} /, / \mathrm{i} /, / \mathrm{u} /, / \mathrm{J} /$, and $/ \mathrm{s} /$. To make measurement of detection easier, for it is sensible to changes in audibility of high-frequency sounds, the phonemes $/ \mathrm{s} /$ and $/ \mathrm{J} /$ were selected, once spectrum peaks are $6,000 \mathrm{~Hz}$ for $/ \mathrm{s} /$ and $4,000 \mathrm{~Hz}$ for $/ \int /$.

Inputs were presented in speakerphone positioned $1 \mathrm{~m}$ behind participants $\left(180^{\circ}\right.$ azimuth) in a sound insulation room. Detection procedure was performed twice for each phoneme in all phases of the study. Phonemes were presented in random order.

\section{Speech perception and spoken word recognition rate}

SPWR was assessed by means of a material recorded by a Brazilian male speaker, made available in a $\mathrm{CD}$, with 25 monosyllables. These were organized in four lists ${ }^{(23)}$. List 1 was presented to the right ear and List 2 to the left ear at $40 \mathrm{dBNS}$. Audiometer Grason Stadler 61 was used. Participants were instructed to repeat the exact same monosyllables they heard. SPWR was established by word correctly repeated count. All participants were assessed without hearing aids in all phases of evaluation.

\section{Fricative phonemes perception rate}

FPP was performed with a software ${ }^{(24)}$ consisting of 24 monosyllables containing the fricative phonemes /s/, /z/, /f/, $/ \mathrm{v} /, / \int /$, and $/ 3 /$ in initial position associated with vowel phonemes $/ \mathrm{a} /, / \mathrm{i} /$, and with or without the fricative $/ \mathrm{s} /$ in final position. Phonetic combinations formed 18 words in Brazilian Portuguese and six combinations forming no word, totaling 24 monosyllables recorded by eight speakers (four females and four males). Therefore, 192 monosyllables composed the test material.

The test was performed in free field in an acoustical enclosure. Inputs were presented with the audiometer Grason Stadler 61 equipped with speaker/microphone. Participants were positioned $1 \mathrm{~m}$ ahead the audiometer ( $0^{\circ}$ azimuth). Sound stimuli were presented at $65 \mathrm{~dB}(\mathrm{~A})$. In the beginning of each evaluation, participants practiced with 10 words randomly presented by the software. All participants were supposed to point out the answers on a board with 24 written monosyllables, right after two presentations of the same word (obligatory test condition). Final scores were released by the FPP software.

\section{Self-assessment questionnaire}

APHAB comprised 24 items used for measuring self-perceived benefits from hearing aids. Questions were divided into four subscales: ease of communication (EC), reverberation (RV), background noise (BN), and aversive stimuli (AV). This fourth subscale measures negative reactions to background sounds. In this study, limitations referred by patients were assessed by subscales, and benefits were not object of study. Therefore, the higher the score, the greater the limitation. Results by subscale are presented in percentage of difficulty to hear, from 0 to $100 \%$. Participants answered the APHAB questionnaire at the beginning of the study and 3, 6, and 12 months after hearing aid adaptation.

\section{Statistical method}

Analysis of variance (ANOVA) for repeated measures was used to assess the effects of FC in verbal behavior tests. When results were statistically significant $(\mathrm{p}<0.05)$, interactions were analyzed by corrected Bonferroni test associated with $t$-test. All statistical analyses were made using Statistical Package for the Social Sciences (SPSS) software, version 17.

\section{RESULTS}

\section{Consonant sound detection}

The results obtained per group for the consonant sound detection test are shown in Figures 1 and 2. Comparison between groups by ANOVA showed difference: phonemes $/ \mathrm{s} /(\mathrm{F}(1.320)=17.2 ; \mathrm{p}<0.02)$ and $/ \int /(\mathrm{F}(1.320)=16.8 ; \mathrm{p}<0.04)$. Figures 1 and 2 also showed detection of consonant sounds in each moment of evaluation. Difference between the first and third moments of the study was observed, in comparison between groups $(\mathrm{F}(1.192)=27.6 ; \mathrm{p}=0.01)$.

\section{Recorded speech perception and recognition rate}

SPWR per group is shown in Table 1. Although results varied a little between participants, one-way ANOVA showed that the effect of long-term acclimatization was different in the experimental group $(\mathrm{F}(1.288)=60.4 ; \mathrm{p}<0.016)$, but not in control group $(\mathrm{F}(1.288)=54.3 ; \mathrm{p}=0.237)$. Also, a significant difference was observed between the first and the third moments of the evaluation $(\mathrm{F}(1.192)=73.2 ; \mathrm{p}<0.001)$.

\section{Fricative phoneme perception rate}

The rates of FPP per group are presented in Table 2. Values of experimental group improved with time, and after three months, absolute measures with FC were higher than those of individuals who did not have it activated. A significant difference was observed between groups $(F(1.320)=49.2$; 


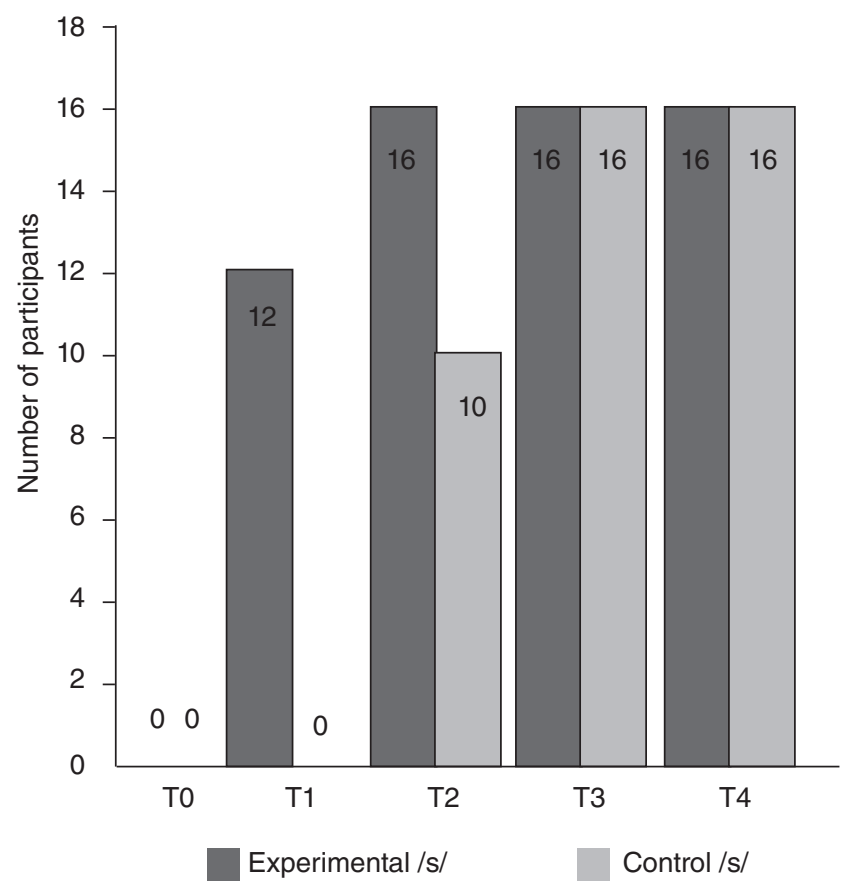

Caption: $\mathrm{TO}=$ hearing aid preadaptation; $\mathrm{T} 1$ = first month of hearing aid adaptation; T2 = third month of hearing aid adaptation; T3 = sixth month of hearing aid adaptation; T4 $=12$ th month of hearing aid adaptation

Figure 1. Number of participants from experimental and control groups who detected the phoneme /s/, according to moment of evaluation

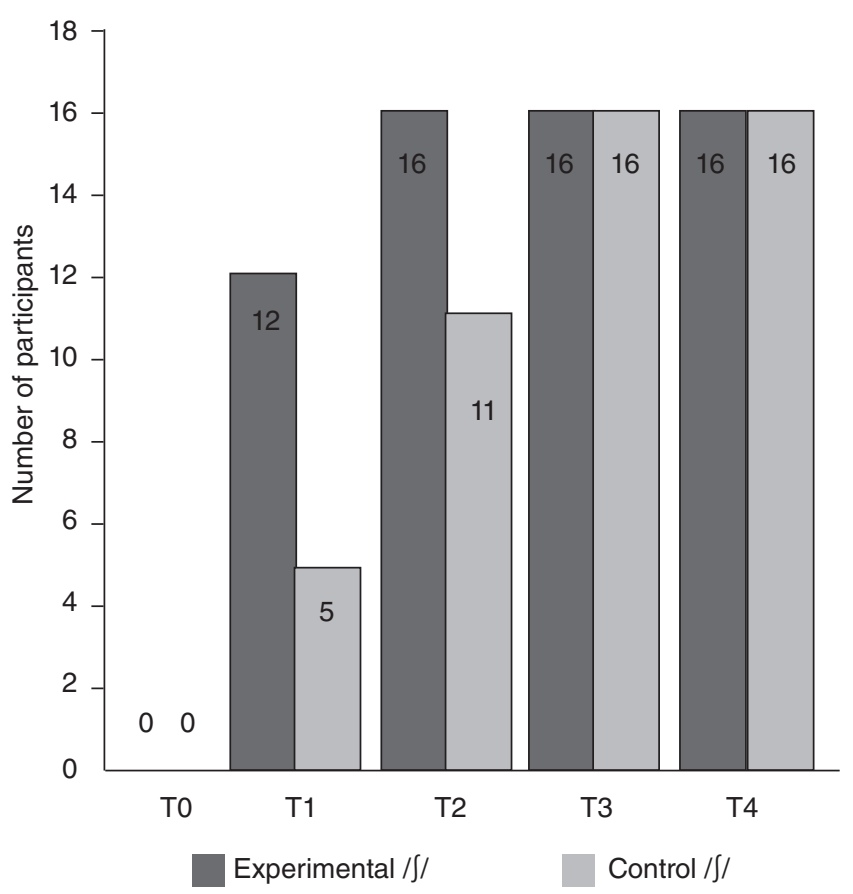

Caption: $\mathrm{TO}=$ hearing aid preadaptation; $\mathrm{T} 1=$ first month of hearing aid adaptation; $\mathrm{T} 2$ = third month of hearing aid adaptation; $\mathrm{T} 3=$ sixth month of hearing aid adaptation; T4 = 12th month of hearing aid adaptation

Figure 2. Number of participants from experimental and control groups who detected the phoneme $/ \mathrm{J} /$, according to moment of evaluation $\mathrm{p}<0.001)$. Therefore, we may say that participants with FC activated in all moments of the study were more benefited than those without it. Furthermore, comparison between the first and third moments was also statistically significant $(\mathrm{F}(1.160)=61.1 ; \mathrm{p}=0.03)$.

\section{Self-assessment questionnaire}

APHAB answers were registered according to the standard procedure to determine the frequency of hearing impairments in daily life of each subscale. ANOVA test showed significant differences $(p<0.001)$ in evaluations with and without hearing aids in three subscales in both groups when the five moments of the study were analyzed: EC, RV, and BN. Only the experimental group showed significant difference in subscale AV $(\mathrm{p}<0.001)$ at long term. Table 3 shows mean values and standard deviations of APHAB scores for each group. There was no difference between them $(\mathrm{F}(1.320)=2.3 ; \mathrm{p}=0.22)$.

\section{DISCUSSION}

This study aimed to assess the effect of FC on speech perception of adults with moderate to severe high-frequency hearing loss throughout 12 months. Supporting our hypothesis that speech perception could improve when FC is activated, verbal behavior tests showed higher scores with FC activated compared to FC deactivated. This improvement in verbal behavior tests was consistent with long-term use, which can be considered an effect of technology acclimatization. Acclimatization was considered by some studies $^{(25-28)}$ as an evident process only after several weeks of amplification.

Detection of /s/ and / $/$ / was different when FC was activated after three months in use as compared to FC deactivated, which suggest benefits only after long periods of acclimatization. Benefits of activated FC in the detection of high frequency sounds (/s/ and $/ / /)$ that was seen after three months of study were maintained after 6 and 12 months of continuous use, to the detriment of deactivated FC. These findings support the long-term use of $\mathrm{FC}$ as responsible for the improvement of simple detection of high-frequency sounds, and this improvement can be immediate with the offer of more audibility. A possible explanation for it is that adults need more time to detect a new compressed signal, unfamiliar in their daily lives.

SPWR was selected in this study to assess the effects of acclimatization. Results of the test were better with activated compared to deactivated FC. Improvement in SPWR can be ascribed to a learning curve and to acclimatization. This is consistent with the results from a study in which adults with hearing loss showed improvement in speech intelligibility when audibility was provided to high-frequency speech ${ }^{(29)}$.

FPP was selected to measure high-frequency phonemes, including fricative sounds. These phonemes were assessed because they can be detected with FC, unlike a frequency 
Table 1. Mean and standard deviation of speech perception and spoken word recognition rate per moment of evaluation and group

\begin{tabular}{|c|c|c|c|c|c|}
\hline Group & $\begin{array}{c}\text { T0 } \\
\text { Mean (SD) }\end{array}$ & $\begin{array}{c}\mathrm{T} 1 \\
\text { Mean (SD) }\end{array}$ & $\begin{array}{c}\text { T2 } \\
\text { Mean (SD) }\end{array}$ & $\begin{array}{c}\text { T3 } \\
\text { Mean (SD) }\end{array}$ & $\begin{array}{c}\text { T4 } \\
\text { Mean (SD) }\end{array}$ \\
\hline \multicolumn{6}{|c|}{ Experimental } \\
\hline Right & $63.3(7.5)$ & $66.5(6.8)$ & $76.0(7.3)$ & $77.0(7.1)$ & $78.0(6.9)$ \\
\hline Left & $61.8(7.4)$ & $67.3(7.2)$ & $74.3(6.4)$ & $77.0(5.2)$ & $75.0(5.9)$ \\
\hline \multicolumn{6}{|l|}{ Control } \\
\hline Right & $62.3(6.2)$ & $63.3(4.9)$ & $70.3(6.9)$ & $72.0(5.5)$ & $72.3(7.1)$ \\
\hline Left & $61.5(8.1)$ & $61.8(5.7)$ & $69.3(8.2)$ & $70.8(7.0)$ & $70.3(7.6)$ \\
\hline
\end{tabular}

Caption: $\mathrm{T} 0=$ hearing aid preadaptation; $\mathrm{T} 1=$ first month of hearing aid adaptation; $\mathrm{T} 2=$ third month of hearing aid adaptation; $\mathrm{T} 3=$ sixth month of hearing aid adaptation; T4 = 12th month of hearing aid adaptation

Table 2. Mean and standard deviation of rates of fricative phonemes perception per moment and group

\begin{tabular}{|c|c|c|c|c|c|}
\hline Group & $\begin{array}{c}\text { T0 } \\
\text { Mean (SD) }\end{array}$ & $\begin{array}{c}\mathrm{T} 1 \\
\text { Mean (SD) }\end{array}$ & $\begin{array}{c}\text { T2 } \\
\text { Mean (SD) }\end{array}$ & $\begin{array}{c}\text { T3 } \\
\text { Mean (SD) }\end{array}$ & $\begin{array}{c}\text { T4 } \\
\text { Mean (SD) }\end{array}$ \\
\hline \multicolumn{6}{|c|}{ Experimental } \\
\hline$f-v$ & $61.3(28.2)$ & $83.4(13.8)$ & $93.2(7.1)$ & $98.2(2)$ & $99.4(0.9)$ \\
\hline$s-z$ & $68.1(21.3)$ & $84.2(8.2)$ & $86.9(2.7)$ & $86.9(3.7)$ & $90.1(5.6)$ \\
\hline $\int-3$ & $29.6(18.8)$ & 57.5 (21.9) & $72.2(11.3)$ & $87.7(9.2)$ & $91.2(5.1)$ \\
\hline Final S & $72.6(24.4)$ & $92.5(13)$ & $98.8(1.8)$ & $99.8(0.5)$ & $99.9(0.1)$ \\
\hline \multicolumn{6}{|l|}{ Control } \\
\hline$f-v$ & $73.4(19.8)$ & $81.9(20.4)$ & $93.0(5.0)$ & $98.9(1.3)$ & $98.9(1.3)$ \\
\hline$s-z$ & $73.4(16.5)$ & 77.9 (16.5) & $86.0(4.7)$ & $85.6(6.1)$ & $86.7(6.8)$ \\
\hline $\int-3$ & $33.4(22.2)$ & $48.2(24.1)$ & $72.9(12.7)$ & $78.7(7.4)$ & $78.6(7.3)$ \\
\hline Final S & $82.0(15.0)$ & $94.8(7.0)$ & $98.8(1.6)$ & $99.8(0.4)$ & $99.8(0.4)$ \\
\hline
\end{tabular}

Caption: $\mathrm{T} 0=$ hearing aid preadaptation; $\mathrm{T} 1=$ first month of hearing aid adaptation; $\mathrm{T} 2=$ third month of hearing aid adaptation; $\mathrm{T} 3=$ sixth month of hearing aid adaptation; $\mathrm{T} 4=12$ th month of hearing aid adaptation

Table 3. Mean and standard deviation of Abbreviated Profile of Hearing Aid Benefit questionnaire in each subscale per moment and group

\begin{tabular}{|c|c|c|c|c|c|}
\hline Grupo & $\begin{array}{c}\text { T0 } \\
\text { Mean (SD) }\end{array}$ & $\begin{array}{c}\mathrm{T} 1 \\
\text { Mean (SD) }\end{array}$ & $\begin{array}{c}\mathrm{T} 2 \\
\text { Mean (SD) }\end{array}$ & $\begin{array}{c}\text { T3 } \\
\text { Mean (SD) }\end{array}$ & $\begin{array}{c}\text { T4 } \\
\text { Mean (SD) } \\
\end{array}$ \\
\hline \multicolumn{6}{|c|}{ Experimental } \\
\hline $\mathrm{FC}$ & $63.4(21.1)$ & $27.1(20.8)$ & $27.2(25.6)$ & $15.9(16.7)$ & $12.2(15.1)$ \\
\hline $\mathrm{RV}$ & $54.9(18.4)$ & $36.4(13.2)$ & $34.3(17.1)$ & $32.2(18.9)$ & $31.3(19.4)$ \\
\hline RA & $60.8(19.7)$ & $32.7(19.6)$ & $29.2(20.1)$ & $20.6(18.5)$ & $21.3(18.2)$ \\
\hline $\mathrm{AV}$ & $50.1(22.8)$ & $45.3(26.9)$ & $39.8(31.7)$ & $22.9(24.5)$ & 17.9 (22.8) \\
\hline \multicolumn{6}{|c|}{ Controle } \\
\hline $\mathrm{FC}$ & $72.3(21.7)$ & $45.6(24.8)$ & $37.9(29.1)$ & 27.9 (17.8) & $19.3(13.9)$ \\
\hline $\mathrm{RV}$ & $57.9(14.4)$ & $44.4(14.8)$ & $39.1(19.6)$ & 41.9 (15.3) & $4.8(15.4)$ \\
\hline RA & 71.7 (18.3) & $41.9(17.1)$ & $41.2(20.3)$ & $31.6(15.6)$ & $32.1(14.6)$ \\
\hline $\mathrm{AV}$ & $40.4(27.1)$ & $36.1(28.8)$ & $35.2(25.7)$ & $25.4(29.4)$ & 17.6 (22.6) \\
\hline
\end{tabular}

Caption: T0 = hearing aid preadaptation; T1 = first month of hearing aid adaptation; T2 = third month of hearing aid adaptation; T3 = sixth month of hearing aid adaptation $\mathrm{T} 4=12$ th month of hearing aid adaptation; $\mathrm{EC}=$ ease of communication; $\mathrm{RV}=$ reverberation; $\mathrm{BN}=$ background noise; $\mathrm{AV}=\mathrm{aversive}$ stimuli

band in a conventional amplification process $(<5,000-$ $6,000 \mathrm{~Hz})$, which is narrow. FPP results improved with $\mathrm{FC}^{(14,16,20)}$, which is consistent with findings from other studies on the subject and well expected, as changes provided by FC are specific for high frequency. Participants who had FC activated had nearly $100 \%$ rate of correct answers in the test after 12 months of continuous use.

However, APHAB scores did not reflect this improvement, just like the findings of other studies regarding $\mathrm{FC}^{(14,16)}$, in which benefits of $\mathrm{FC}$ varied between individuals. 
APHAB scores related to limitations in different environments showed no long-term differences between groups. Experimental group had a difference along time in AV scale. For all three APHAB subscales (EC, RV, and BN) groups differed, just like in a previous study ${ }^{(30)}$.

Subscale AV score is usually higher after hearing aids adaptation. This probably reflects the increase in audibility of certain environmental sounds that normal-hearing individuals may find uncomfortable. Control group had higher results (upper limit) when compared to experimental group. This finding may be related to FC activation.

Although FC brings benefits for speech perception, results from the self-assessment questionnaire indicate little difference in subjective assessments in both groups. These findings are consistent with the literature ${ }^{(19)}$. Audiologists should therefore be aware that a patient can be significantly benefited from FC, even though results of self-assessment suggest the contrary. Results of speech perception must be measured with and without FC, so the technician can advise patients more effectively. This study brought evidence that the greatest benefits of FC can be seen when individuals have more time to adapt to their hearing aids. Another recent study evaluated the use of hearing aids with FC reported progressive improvement in speech perception along 6 months in children $^{(20)}$. Therefore, these results can be compared to our findings in adults.

It is important to highlight that prolonged improvement in speech perception may result from the need of continuous exposure to FC signal in daily life, so the individuals can learn to recognize it.

At the end of the study, all participants who had FC activated chose to keep the algorithm activated, whereas 10 participants with FC deactivated chose to activate it. Six participants with FC deactivated decided to keep it this way, for that is how they preferred the quality of the sound.

Further studies should extend verbal behavior tests to participants with other hearing loss levels in order to develop protocols to support decisions related to FC.

\section{CONCLUSION}

This study showed that FC in adults provides early improvement of audibility, detection of phonemes /s/ and / $/ \mathrm{f}$, SPWR, and FPDR. Limitations of hearing loss in daily life were reduced regardless of the activation of the algorithm.

\section{ACKNOWLEDGMENTS}

Coordenação de Aperfeiçoamento de Pessoal de Nível Superior (CAPES) is acknowledged for the financing of this research.

*VCM was responsible for literature research, data collection and organization, writing of the paper; MCMI was responsible for the study design, orientation of study phases, and approval of final version.

\section{REFERENCES}

1. Van Vliet D. Is there a hearing aid that can...? Hear J. 1999;52(10):100.

2. Horwitz AR, Ahlstrom JB, Dubno JR. Factors affecting the benefits of high frequency amplification. J Speech Lang Hear Res. 2008;51:798-813.

3. Baer T, Moore BC, Kluk K. Effects of low pass filtering on the intelligibility of speech in noise for people with and without dead regions at high frequencies. J Acoust Soc Am. 2002;112:1133-44.

4. Gordo A, Iorio MCM. Zonas mortas na cóclea em frequências altas: implicações no processo de adaptação de próteses auditivas. Rev Bras Otorrinolaringol. 2007;73(3):299-307.

5. Cox RM, Johnson JA, Alexander GC. Implications of high frequency cochlear dead regions for fitting hearing aids to adults with mild to moderately severe hearing loss. Ear Hear. 2012;33(5):573-87.

6. Plyer PN, Fleck EL. The effects of high frequency amplification on the objective and subjective performance of hearing instrument users with varying degrees of high frequency hearing loss. J Speech Hear Res. 2006;49:616-27.

7. Turner CW, Henry BA. Benefits of amplification for speech recognition in background noise. J Acoust Soc Am. 2002;112(4):1675-80.

8. Pittman AL. Short term word learning rate in children with normal hearing and children with hearing loss in limited and extended high frequency bandwidths. J Speech Hear Res. 2008;51:785-97.

9. Pittman AL, Lewis DE, Hoover BM, Stelmachowicz PG. Rapid word learning in normal hearing and hearing impaired children: effects of age, receptive vocabular, and high frequency amplification. Ear Hear. 2005;26(6):619-29.

10. Stelmachowicz PG, Lewis DE, Hoover B. The effects of stimulus bandwidth on auditory skills in normal hearing and hearing impaired children. Ear Hear. 2007;28(4):483-94.

11. Stelmachowicz PG, Pittman AL, Hoover BM, Lewis DE. Effect of stimulus bandwidth on the perception of $/ \mathrm{s} /$ in normal and hearingimpaired children and adults. J Acoust Soc Am. 2001;110:2183-90.

12. Stelmachowicz PG, Pittman AL, Hoover BM, Lewis DE, Moeller MP. The importance of high-frequency audibility in the speech and language development of children with hearing loss. Arch Otolaryngol Head Neck Surg. 2014;130(5):556-62.

13. McDermott HJ. New solutions for high frequency hearing impairment. J Hear Sci. 2012;5(1):1-34

14. Simpson A, Hersbach AA, McDermott HJ. Improvements in speech perception with in an experimental nonlinear frequency compression hearing device. Int J Audiol. 2005;44(5):281-92.

15. Vickers DA, Moore BCJ, Baer T. Effects of low-pass filtering on the intelligibility of speech in quiet for people with dead regions at high frequencies. J Acoust Soc Am. 2001;110(2):1164-75.

16. Glista D, Scollie S, Bagatto M, Seewald R, Parsa V, Johnson A. Evaluation of nonlinear frequency compression: clinical outcomes. Int $\mathrm{J}$ Audiol. 2009;48(9):632-44

17. Baker A [Internet]. Critical review: effects of multi-channel, nonlinear frequency compression on speech perception in hearing impaired listeners with high frequency hearing loss. 2010 [cited 2015 Jan 11]. Available from: http://www.uwo.ca/fhs/csd/ebp/reviews/2009-10/ Baker-Aud.pdf

18. Bagatto M, Scollie S, Glista D, Pasa V [Internet]. Case study outcomes of hearing-impaired listeners using nonlinear frequency compression technology [cited 2015 Jan 11]. Available from: http://www. audiologyonline.com/articles/case-study-outcomes-hearing-impaired-925

19. Simpson A, Hersbach AA, McDermott HJ. Frequency-compression outcomes in listeners with steeply sloping audiograms. Int J Audiol. 2006;45:619-29.

20. Wolfe J, John A, Schafer E, Nyffeler M, Boretzki M, Caraway T, et al. Long term effects of nonlinear frequency compression for children with moderate hearing loss. Int J Audiol. 2011;50:396-404.

21. Glista D, Easwar V, Purcell DW, Scollie S. A pilot study on cortical auditory evoked potentials in children: aided caeps reflect improved highfrequency audibility with frequency compression hearing aid technology. Int J Otolaryngol. 2012;2012:982894. 
22. Hopkins K, Khanom M, Dickinson, AM, Munro KJ. Benefit from nonlinear frequency compression hearing aids in a clinical setting: The effects of duration of experience and severity of high-frequency hearing loss. Int J Audiol. 2014;53:219-28.

23. Pen M, Mangabeira-Albernaz, PL. Desenvolvimento de teste de logoaudiometria: discriminação vocal. In: $2^{\circ}$ Congresso Pan Americano de Otorrinolaringologia y Broncoesofasologia; 1973; Lima. Anales. v. 2. Lima: [s.n.]; 1973:223-6.

24. Prates LPCS. Compressão de frequências e suas implicações no reconhecimento de fala [tese]. São Paulo: Universidade Federal de São Paulo; 2009.

25. Cox RM, Alexander GC. Maturation of hearing aid benefit: objective and subjective measurements. Ear Hear. 1992;13(3):131-41.
26. Cox RM, Alexander GC, Taylor IM, Gray JA. Benefit acclimatization in elderly hearing aid users. J Am Acad Audiol. 1996;7:428-41.

27. Gatehouse $\mathrm{S}$. The time course and magnitude of perceptual acclimatization to frequency responses: evidence from monaural fitting of hearing aids. J Acoust Soc Am. 1992;92:1258-68

28. Munro KJ, Lutman ME. The effect of speech presentation level on measurement of auditory acclimatization to amplified speech. J Acoust Soc Am. 2003;114:484-95.

29. Hornsby BW, Johnson EE, Picou E. Effects of degree and configuration of hearing loss on the contribution of high- and low-frequency speech information to bilateral speech understanding. Ear Hear. 2011;32(5):543-55.

30. Cox RM, Alexander GC. The abbreviated profile of hearing aid benefit. Ear Hear. 1995;16(2):176-86. 